\title{
ÍNDICES MORFOFISIOLGICOS E PRODUÇÃO DE PIMENTÃO PRODUZIDO EM DIFERENTES SUBSTRATOS A BASE DE RESÍDUOS ORGÂNICOS EM AMBIENTE PROTEGIDO
}

\author{
Luana Keslley Nascimento Casais1; Rhaiana Oliveira de Aviz2; Núbia de Fátima Alves Santos3; Márcio \\ Roberto da Silva Melo4; Vitor Quintela de Souza5; Luciana da Silva Borges6; Anna karoliny Oliveira \\ Lima7; Amaralina Celoto Guerreiro8.
}

\begin{abstract}
1Universidade Federal Rural da Amazônia, Paragominas, Pará, Brasil, luana.casais@gmail.com Universidade Federal Rural da Amazônia, Paragominas, Pará, Brasil, rhaianaoliveiradeaviz@gmail.com

3Universidade Federal Rural da Amazônia, Paragominas, Pará, Brasil, quintelav@gmail.com 4Universidade Federal Rural da Amazônia, Paragominas, Pará, Brasil, oliverannakarol@gmail.com 5Universidade Federal Rural da Amazônia, Paragominas, Pará, Brasil, nubia.santos@ufra.edu.br 6Universidade Federal Rural da Amazônia, Paragominas, Pará, Brasil, marcio.melo@ufra.edu.br 7Universidade Federal Rural da Amazônia, Paragominas, Pará, Brasil, luciana.borges@ufra.edu.br 8Universidade Federal da Paraíba, Pombal, Paraíba, Pará, maracguerrero@hotmail.com
\end{abstract}

RESUMO: O pimentão (Capsicum annuum L.) é uma das dez hortaliças de maior importância econômica no mercado brasileiro. O uso de substrato para produção de pimentão, é uma alternativa, para uso intensivo dos solos, em casa de vegetação. E diminuição das doenças de solos que afetam a produção dessa hortaliça em ambiente protegido. Objetivou-se com este trabalho avaliar os índices morfofisiológicos e a produção de pimentão em diferentes substratos alternativos, no município de Paragominas, Pará. O experimento foi realizado na Universidade Federal Rural da Amazônia, utilizando delineamento experimental em esquema fatorial $5 \times 2$, sendo 5 substratos e duas cultivares, sendo os substratos: 1 - testemunha; 2 - Resíduo de soja; 3 - palha de arroz; 4 - Terra preta; 5 - Terra preta + Palha de arroz + Resíduo de soja, e as cultivares casca dura Ikeda e Rubi Gigante e quatro repetiç̃̃es. As médias comparadas pelo teste de Tukey a $1 \%$ de probabilidade. Foram avaliadas as características altura de plantas $(\mathrm{cm})$, diâmetro de colo $(\mathrm{mm})$, massa fresca $(\mathrm{g})$, quantidade de frutos, massa seca (g), área foliar, Médias da Razão de Área Foliar (RAF), Razão de Peso das Folhas (RPF), Área Foliar Específica (AFE), Peso específico foliar (PEF), Quantidade de água na parte aérea (QAPA) e Índice de área foliar (IAF). A cultivar Casca dura Ikeda apresentou resultados satisfatórios, referentes às características avaliadas nas condições climáticas do município de Paragominas. Em relação ao desempenho do substrato, a cultivar Casca Dura Ikeda apresentou melhor rendimento no substrato resíduo de soja.

PALAVRAS-CHAVE: Capsicum annuum, Resíduos orgânicos, Substrato alternativo. 


\title{
MORPHOPHYSIOLOGICAL INDICES AND PEPPER PRODUCTION PRODUCED ON DIFFERENT SUBSTRATES BASED ON ORGANIC RESIDUES IN PROTECTED ENVIRONMENT
}

\begin{abstract}
The pepper (Capsicum annuum L.) is one of the ten vegetables of major economic importance in the Brazilian market. The use of substrate for pepper production is an alternative, for intensive use alone. And the demise of soil diseases that affect the production of this vegetable. The objective of this work was to evaluate morphophysiological indices and pepper production in different alternative substrates in the city of Paragominas, Pará. The experiment was carried out at the Federal Rural University of Amazonia, using an experimental design in a 5x2 factorial scheme with two cultivars, being substrate and two cultivars, the substrates being: 1 - control; 2 Soya residue; 3 - rice straw; 4 - Black earth; 5 - Black soil + Rice straw + Soybean residue, and hard shell cultivars Ikeda and Rubi Gigantic and four replicates. With averages compared by the Tukey test at $1 \%$ probability. The plant height $(\mathrm{cm})$, leaf diameter (mm), fresh mass (g), number of fruits, dry mass (g), foliar area, leaf area ratio (RAF) (AFP), leaf specific weight (PEF), amount of water in the aerial part (QAPA) and leaf area index (LAI). The cultivar Casca dura Ikeda presented satisfactory results, referring to the characteristics evaluated in the climatic conditions of the municipality of Paragominas. Regarding the substrate performance, the cultivar Casca Dura Ikeda presented better yield in the substrate soy residue.
\end{abstract}

KEYWORDS: Alternate substrate, Capsicum annuum, Organic waste.

\section{ÍNDICES MORFOFISIOLGICOS Y PRODUCCIÓN DE PIMIENTO PRODUCIDO EN DIFERENTES SUSTRATOS A BASE DE RESIDUOS ORGÁNICOS EN UN AMBIENTE PROTEGIDO}

RESUMEN: El pimiento (Capsicum annuum L.) es una de las diez hortalizas de mayor importancia económica e $n$ el mercado brasileño. El uso de sustrato para la producción de pimiento, es una alternativa, para uso intensivo suelos. Y dimensión de las enfermedades de suelo que afectan la producción de esas hortalizas. El objetivo de este trabajo es evaluar el índice morfofisiológico y la producción de pimiento en diferentes sustratos alternativos en el municipio de Paragominas, Pará. El experimento fue realizado en la Universidad Federal Rural de la Amazonia, utilizando delineamiento experimental en esquema factorial $5 \times 2$, con dos cultivares, Siendo 5 sustrato y dos cultivares, siendo los sustratos: 1 - testigo; 2 - Residuo de soja; 3 - paja de arroz; 4 Tierra negra; 5 - Tierra negra + Paja de arroz + Residuo de soja, y los cultivares cáscara dura Ikeda y Rubí Gigante y cuatro repeticiones. Con medias comparadas por el test de Tukey al 1\% de probabilidad. Se evaluaron las características altura de plantas (cm), 
diámetro de cuello (mm), masa fresca (g), cantidad de frutos, masa seca (g), área foliar, Promedios de la Razón de Área Foliar (RAF), Razón de Peso de las hojas (RPF), Área Foliar específica (AFE), Peso específico foliar (PEF), Cantidad de agua en la parte aérea (QAPA) e Índice de área foliar (IAF). La cultivar Casca dura Ikeda presentó resultados satisfactorios, referentes a las características evaluadas en las condiciones climáticas del municipio de Paragominas. En relación al desempeño del sustrato, la cultivar Casca Dura Ikeda presentó mejor rendimiento en el sustrato residuo de soja.

PALABRAS CLAVE: Capsicum annuum, Residuos orgânicos, Sustrato alternativo.

Estado do Pará, segundo maior estado brasileiro e com 6,5 milhões de habitantes tem no seu PIB três grandes atividades, que são a mineração, a extração de madeira e a pecuária. Grande parte das hortaliças consumidas no estado é importada. A região norte consome menos hortaliças no país, em função dos aspectos culturais, do preço elevado e da dificuldade de acesso às hortaliças por parte da maioria da população. Os desafios são grandes em um cenário de condições adversas, e onde as demandas pelo aumento da produção de hortaliças vêm forçando ações mais propositivas.

O pimentão (Capsicum annuum L.) é uma das dez hortaliças de maior importância econômica no mercado brasileiro. Planta bastante exigente quanto à fertilidade do solo e, por conta disso faz-se uso de adubações orgânica e mineral, para torná-los compatíveis com as exigências da cultura. Resultados de pesquisas têm mostrado a importância da utilização de doses elevadas de adubos orgânicos e minerais para atender à demanda de nutrientes na cultura do pimentão (MELO et al., 2000; RIBEIRO et al., 2000; OLIVEIRA et al., 2004).

O cultivo de hortaliças atualmente em ambiente protegido, entre as elas o pimentão, assume a cada dia mais importância, porque permite a produção em diferentes épocas, alcançando melhores preços no mercado. Em ambiente protegido como medida preventiva na 
degradação do solo, se tem utilizado o cultivo em substratos, promovendo, incrementos na produtividade e na qualidade dos frutos. Neste sistema, são fornecidas às plantas quantidades de nutrientes adequadas para cada estádio fenológico (CHARLO et al., 2009).

Um substrato agrícola é todo material, natural ou artificial, colocado em um recipiente, puro ou em mistura, que permite a fixação do sistema radicular e serve para suportar a planta (FERNANDES et al., 2000), podendo ainda regular a disponibilidade de nutrientes para as raízes (CALVETE et al., 2000).

Para Casais (2017) é importante ter alternativas que venham a desonerar cada vez mais o custo de substratos, neste que é um importante processo da cadeia produtiva, para melhoria de produção. Com isso faz-se, necessidade de aproveitar os resíduos orgânicos locais.

Os resíduos orgânicos representam metade dos resíduos sólidos urbanos gerados no Brasil e podem ser tratados em várias escalas, desde a escala doméstica, passando pela escala comunitária, institucional (de um grande gerador de resíduos), municipal até a escala industrial, para a produção de fertilizante orgânico (MMA, 2017).

A utilização dos resíduos alternativos no arranjo dos substratos significa uma alternativa para a reciclagem de resíduos agroindustriais, bem como para aquisição de misturas ideais que sirvam de suporte para o desenvolvimento das plantas (PRAGANA, 1998). É nesse contexto que o presente trabalho busca trazer novos conhecimentos no que concerne índices morfofisiológicos e a produção de pimentão em diferentes substratos alternativos, no município de Paragominas, Pará. Visando O aproveitamento de recursos existentes na região norte.

O experimento foi conduzido na Universidade Federal Rural da Amazônia, campus de Paragominas, na área experimental de Horticultura UFRA. O município de Paragominas está entre as coordenadas geográficas 
$02^{\circ} 5^{\prime} 24^{\prime \prime} \mathrm{S}$ e $47^{\circ} 34^{\prime} 36^{\prime \prime}$ W. O clima da região é do tipo Awi, segundo a classificação de Köppen, isto é, tropical chuvoso com estação seca bem definida, com temperatura média anual de $26,5^{\circ} \mathrm{C}$. A umidade relativa do ar varia de $70 \%$ a $90 \%$ (RODRIGUES et al., 2002).

Esse ensaio foi realizado em vasos com capacidade de $5 \mathrm{~L}$, no período de altas temperaturas. As plantas foram conduzidas em estrutura de cultivo protegido, de $20 \mathrm{~m}$ de comprimento, $8 \mathrm{~m}$ de largura e pé direito de 2,5m, coberto com filme plástico de polietileno 100 micra. Foi utilizado o delineamento experimental em esquema fatorial $5 \times 2$, sendo 5 substratos e duas cultivares, sendo os substratos: 1 - testemunha; 2 - Resíduo de soja; 3 - palha de arroz; 4 - Terra preta; 5 - Terra preta (30\%)+ Palha de arroz(35\%) + Resíduo de soja (35\%), e as cultivares casca dura Ikeda e Rubi Gigante e quatro repetições, cada parcela é constituída de seis plantas, das quais quatro foram utilizadas para avaliação dos parâmetros de produção, as demais foram consideradas bordaduras.

Em relação à origem e características dos substratos, o resíduo de soja foi obtido em uma empresa de grãos, localizada no município de Paragominas. Antes de ser colocado nas bandejas, foi peneirado com peneira tipo pedreiro em aço, com bordas de madeira e $60 \mathrm{~cm}$ de diâmetro, em seguida o substrato foi umedecido os resultados das características químicas encontram-se na Tabela 1.

Em relação à origem e características do substrato palha de arroz foi obtida em uma distribuidora de alimentos, localizada no município de Paragominas, os resultados das características químicas encontram-se na Tabela 2. 
Tabela 1. Análise química do resíduo de soja, adquiridos nas empresas de grãos de Paragominas, Pará, 2016.

\begin{tabular}{|c|c|c|c|c|c|c|c|c|c|}
\hline$P_{\text {Total }}$ & $\mathrm{F}$ & $\mathrm{Ca}$ & $\mathrm{Mg}$ & $\mathrm{Fe}$ & Al & $\mathrm{Cu}$ & $\mathrm{Zn}$ & $\mathrm{Mn}$ & $\mathrm{Na}$ \\
\hline \multicolumn{6}{|c|}{ 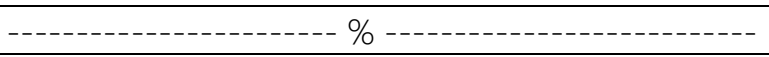 } & \multicolumn{4}{|c|}{--------------------- ppm -------------------- } \\
\hline 0,4 & 0,08 & 0,04 & 0,05 & 2,67 & 5,22 & 0 & 58,06 & 99,38 & 273,81 \\
\hline B & M.O. & Umidade & $S$ & $N_{\text {Total }}$ & Cinzas & $\mathrm{pH}\left(\mathrm{CaCl}_{2}\right)$ & Mo & $\mathrm{Co}$ & Densidade \\
\hline \multicolumn{7}{|c|}{ 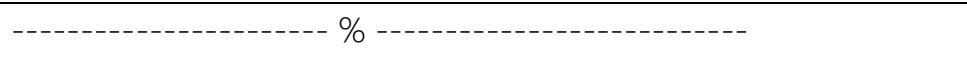 } & \multicolumn{2}{|c|}{----- ppm ----- } & $\mathrm{g} / \mathrm{cm}^{3}$ \\
\hline 0,01 & 57,34 & 14,73 & 0 & 0,47 & 42,66 & 4,8 & 8,67 & 0 & 0,2 \\
\hline
\end{tabular}

Onde: P) resina-Fósforo; (a) Cálcio; Mg) Magnésio; Fe) Ferro; Al) Alumínio; ( Cu) Cobre; Zn) Zinco; Mn) Manganês; Na) Sódio; B) Boro; M.O.) Matéria Orgânica; S) Enxofre; N) Nitrogênio; Mo) Molibdênio; Co) Cobalto.

Fonte: IBRA Laboratório.

Tabela 2. Análise química da palha de arroz, adquiridos em uma distribuidora de alimentos, Paragominas, Pará, 2016.

\begin{tabular}{cccccccccc}
\hline PTotal & $\mathrm{F}$ & $\mathrm{Ca}$ & $\mathrm{Mg}$ & $\mathrm{Fe}$ & $\mathrm{Al}$ & $\mathrm{Cu}$ & $\mathrm{Zn}$ & $\mathrm{Mg}$ & $\mathrm{Na}$ \\
\hline $\mathbf{- - 1 2}$ & 1,05 & 0,89 & 0,36 & 1,28 & 4,12 & 5,57 & 90,29 & 75,31 & 287,36 \\
\hline B & M.O. & Umidade & Enxofre & $\mathrm{N}_{\text {Total }}$ & Cinzas & $\mathrm{pH}$ & $\mathrm{Mo}$ & $\mathrm{Co}$ & Densidade \\
& & & & & & & & & \\
\hline$-0,01$ & 63,65 & 10,33 & 0 & 2,16 & 36,35 & 7,7 & 9,75 & 2,22 & 0,41 \\
\hline
\end{tabular}

Onde: P) resina-Fósforo; (a) Cálcio; Mg) Magnésio; Fe) Ferro; Al) Alumínio; Cu) Cobre; Zn) Zinco; Mn) Manganês; Na) Sódio; B) Boro; M.O.) Matéria Orgânica; S) Enxofre; N) Nitrogênio; Mo) Molibdênio; Co) Cobalto.

Fonte: IBRA Laboratório.

As mudas foram produzidas em viveiro, com dimensões de $4 \times 12$ metros, pé direito de 3 metros e coberto com sombrite $70 \%$. A produção de mudas foi realizada em bandejas de poliestireno expandido, preenchida com substrato comercial
Plantmax Hortaliças ${ }^{\circledR}$ tipo HT. A semeadura foi feita no dia 10/01/2017 colocando 2 sementes por célula, o desbaste e repicagem foram feitos 14 dias após a semeadura, a irrigação se deu manualmente com a utilização de irrigadores. 
transplante foi realizado quando as mudas estavam com 4 folhas definitivas dispostas em vasos, cada vaso contendo uma muda, colocadas em casa de vegetação, 40 dias após a semeadura. Foi realizada a caracterização das mudas, utilizandose 10 plantas, coletadas aleatoriamente nas bandejas. Foram feitas ao longo do experimento aplicações de ureia $(2 \mathrm{~g} / \mathrm{L})$ e solução nutritiva (1m//L) periodicamente.

Aos 30 dias do transplante as plantas entraram em fase de floração, foi realizada a capação das flores que surgiram com um bisturi cirúrgico a fim de que não gastasse sua energia disponível, no enchimento de frutos, pois ainda estavam em fase de crescimento de planta. Durante parte do cultivo, foram feitas desbrotas dos brotos laterais com auxílio de bisturi cirúrgico, feito isto até que as plantas atingissem a altura adequada para floração e fase de frutos. Para a fixação as plantas foram tutoradas de forma individual com fitilhos plásticos. Nos fitilhos, foi utilizado alceador de maneira a evitar o tombamento da planta.

Entre vasos foi utilizado o espaçamento de 0,3 m. A irrigação utilizada foi por manual, realizadas quatro vezes ao dia pelo fato de o clima da região ser de altas temperaturas e alta umidade. $\mathrm{O}$ controle de plantas daninhas se deu através de retirada manual sempre que necessário para não comprometer as raízes das plantas.

A colheita dos pimentões foi iniciada aos 60 dias após o transplante, quando os frutos apresentavam pelo menos 70\% de sua superfície de cor vermelha. Os frutos colhidos foram conduzidos ao laboratório, onde avaliaram-se o comprimento médio dos frutos (cm), o diâmetro transversal (cm) e longitudinal (cm) médio dos frutos com a utilização de paquímetro digital, produção total por planta onde avaliou-se a quantidade de frutos por cada planta. Massa fresca média (g) dos frutos, pesados em balança digital de precisão e análise destrutiva por planta, foi feito a separação do sistema 
radicular da parte aérea, que foi pesada com auxílio de uma balança digital de precisão.

Após a determinação dessas variáveis em cada amostragem, foi calculado com base nas especificações de Benincasa (2003) a área foliar específica (AFE), estimada pela superfície das folhas e sua massa seca $\left(\mathrm{dm}^{2} \mathrm{~g}-1\right)$, o Índice de área foliar (IAF): determinado através da razão entre os valores da área foliar total e área de solo ocupada pelas plantas (cm²/planta), a Razão de Área Foliar (RAF): Determinada através da razão entre os valores da área foliar total e massa seca total $\left(\mathrm{dm}^{2} \mathrm{~g}^{-1}\right)$,

A Razão de Peso das Folhas (RPF): A razão de peso de folhas é calculada pela razão entre a massa seca de folhas e a massa seca total $\left(g \mathrm{~g}^{-1}\right)$, a Quantidade de água na parte aérea (QAPA) (g por conjunto de plantas): A quantidade de água na parte aérea foi obtida através da diferença entre a massa de matéria fresca e seca da parte aérea das plantas avaliadas (g) e Peso específico foliar (PEF) $\left(\mathrm{g} \mathrm{cm}^{-2}\right.$ por conjunto de plantas): O peso específico foliar foi estimado através da divisão da massa seca da parte aérea pela área foliar $\left(\mathrm{g} \mathrm{dm} \mathbf{-}^{2}\right)$.

Todos os dados obtidos foram analisados estatisticamente através da análise de variância, com teste F. Quando houve significância para os fatores foi aplicado teste de Tukey (1\%) para a comparação de médias. E quando houve a interação significativa foi realizado o desdobramento da interação. Todas as análises realizadas foram feitas pelo programa SISVAR (FERREIRA, 2000).

Verificou-se efeito significativos entre a interação entre os fatores substratos e cultivares de pimentão para as características avaliadas: altura, diâmetro do caule, número de frutos, diâmetro longitudinal e transversal, massa total e área foliar. Demonstrando que tanto o fator substrato como o fator cultivar influenciaram nas qualidades fitotécnicas das plantas (Tabela 3).

A cultivar Casca dura Ikeda mostrou resultados significantes em relação a 
cultivar Rubi Gigante tendo os melhores resultados para todos os substratos para a altura (Tabela 3). 0 substrato Resíduo de soja teve melhor resultado em ambas cultivares. Costa et al. (2013), avaliando o efeito de diferentes substratos na produção de cultivares de pimentão, utilizadas no presente trabalho (Casca dura Ikeda e Rubi Gigante), e verificou respostas variadas de acordo com a cultivar utilizada.

Para o diâmetro do caule, houve interação significativa dos substratos e cultivares (Tabela 3), onde tanto o fator substrato, como o fator cultivar, tiveram interferência nessa variável. Sendo que a cultivar Rubi Gigante no substrato resíduo de soja apresentou melhor rendimento, Segundo Souza et al. (2013), o diâmetro do caule combinado com comprimento da parte aérea, constitui um dos mais importantes caracteres morfológicos.

Pôde-se verificar na Tabela 3, interação significativa entre o fator substrato e o fator cultivar, onde ambos proporcionaram efeito significativo. $\bigcirc$ substrato para o número de frutos favoreceu o bom rendimento por planta (Tabela 3). O substrato mistura obteve resultado relevante em relação aos demais o que o caracterizou como sendo o melhor substrato para produtividade nos frutos, o substrato resíduo de soja obteve resultado semelhante na mesma cultivar. Os resultados aqui obtidos foram superiores aos de Charlo (2009), cultivando o híbrido de pimentão amarelo em ambiente protegido (Tabela 3). 
Tabela 3. Médias da altura das plantas, $n^{\circ}$ de frutos, diâmetro transversal e longitudinal do fruto, massa total dos pimentões e área foliar de cultivares de pimentão Casca Dura Ikeda e Rubi Gigante, cultivados em cinco diferentes substratos, em casa de vegetação.

\begin{tabular}{|c|c|c|c|c|c|c|c|}
\hline SUBSTRATO & $\begin{array}{c}\text { Altura } \\
(\mathrm{cm})\end{array}$ & $\begin{array}{c}\text { Diâm. } \\
\text { Caule } \\
(\mathrm{cm})\end{array}$ & $\begin{array}{l}N^{0} \text { de } \\
\text { frutos }\end{array}$ & $\begin{array}{c}\text { Diâm. } \\
\text { Trans } \\
\text { Fruto } \\
(\mathrm{cm})\end{array}$ & $\begin{array}{c}\text { Diâm. } \\
\text { Long } \\
\text { Fruto } \\
(\mathrm{cm})\end{array}$ & $\begin{array}{c}\text { Massa } \\
\text { total } \\
(\mathrm{g})\end{array}$ & $\begin{array}{l}\text { Área } \\
\text { foliar } \\
\left(\mathrm{cm}^{2}\right)\end{array}$ \\
\hline \multicolumn{8}{|c|}{ RUBI } \\
\hline $\begin{array}{l}\text { Caroço de Açaí } \\
\text { Palha de arroz } \\
\text { Mistura } \\
\text { (PA+RS+C+TP) } \\
\text { T. Preta } \\
\text { Resíduo de Soja }\end{array}$ & $\begin{array}{l}16,02 \mathrm{cB} \\
18,46 \mathrm{cB} \\
28,33 \mathrm{bB} \\
35,29 \mathrm{aB} \\
35,49 \mathrm{aB}\end{array}$ & $\begin{array}{l}3,29 \mathrm{cA} \\
3,66 \mathrm{cB} \\
6,37 \mathrm{bA} \\
6,37 \mathrm{bA} \\
7,70 \mathrm{aA}\end{array}$ & $\begin{array}{l}0,10 \mathrm{~dB} \\
14,46 \mathrm{cA} \\
25,86 \mathrm{aA} \\
23,3 \mathrm{bA} \\
25,74 \mathrm{aA}\end{array}$ & $\begin{array}{c}0,07 \mathrm{~dB} \\
3,00 \mathrm{cA} \\
5,12 \mathrm{aA} \\
3,43 \mathrm{bcA} \\
3,98 \mathrm{bA}\end{array}$ & $\begin{array}{l}0,02 \mathrm{~dB} \\
2,63 \mathrm{cB} \\
3,70 \mathrm{bB} \\
3,16 \mathrm{bcB} \\
4,32 \mathrm{aB}\end{array}$ & $\begin{array}{c}8,26 \mathrm{dA} \\
18,11 \mathrm{cB} \\
29,08 \mathrm{aA} \\
23,03 \mathrm{bB} \\
24,38 \mathrm{bA}\end{array}$ & $\begin{array}{l}8,97 \mathrm{bB} \\
16,54 \mathrm{aB} \\
16,54 \mathrm{aB} \\
16,54 \mathrm{aB} \\
16,04 \mathrm{aA}\end{array}$ \\
\hline \multicolumn{8}{|c|}{ IKEDA } \\
\hline $\begin{array}{l}\text { Caroço de Açaí } \\
\text { Palha de arroz } \\
\text { Mistura } \\
\text { (PA+RS+C+TP) } \\
\text { T. Preta } \\
\text { Resíduo de Soja }\end{array}$ & $\begin{array}{l}20,45 \mathrm{dA} \\
42,37 \mathrm{cA} \\
34,87 \mathrm{bA} \\
46,50 \mathrm{aA} \\
48,45 \mathrm{aA}\end{array}$ & $\begin{array}{l}3,33 \mathrm{cA} \\
7,04 \mathrm{aA} \\
5,70 \mathrm{bB} \\
5,79 \mathrm{bA} \\
6,91 \mathrm{aB}\end{array}$ & $\begin{array}{l}8,54 \mathrm{cA} \\
15,20 \mathrm{bA} \\
14,92 \mathrm{bB} \\
16,28 \mathrm{bB} \\
18,32 \mathrm{aB}\end{array}$ & $\begin{array}{l}2,08 \mathrm{bA} \\
3,11 \mathrm{aA} \\
2,26 \mathrm{bB} \\
2,42 \mathrm{bB} \\
3,71 \mathrm{aA}\end{array}$ & $\begin{array}{l}2,69 \mathrm{cA} \\
4,26 \mathrm{bA} \\
2,75 \mathrm{cA} \\
3,97 \mathrm{bA} \\
5,11 \mathrm{aA}\end{array}$ & $\begin{array}{c}2,50 \mathrm{~dB} \\
22,00 \mathrm{bcA} \\
20,25 \mathrm{cB} \\
31,57 \mathrm{aA} \\
23,73 \mathrm{bA}\end{array}$ & $\begin{array}{l}15,63 \mathrm{cA} \\
30,48 \mathrm{aA} \\
22,04 \mathrm{bA} \\
21,26 \mathrm{bA} \\
10,78 \mathrm{~dB}\end{array}$ \\
\hline Substrato & $\star \star$ & $\star \star$ & ** & 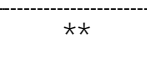 & ** & $\star *$ & $* \star$ \\
\hline Cultivar & $\star *$ & $\star \star$ & $\star \star$ & $\star *$ & $\star \star$ & NS & $\star \star$ \\
\hline$S \times C$ & $\star \star$ & $\star \star$ & $* \star$ & $\star \star$ & $\star \star$ & $\star \star$ & $\star \star$ \\
\hline CV (\%) & 4,11 & 7,76 & 4,26 & 11,37 & 8,76 & 5,58 & 9,68 \\
\hline
\end{tabular}

Médias seguidas pela mesma letra maiúscula corresponde a cultivar não diferem entre si, médias seguidas pela mesma letra minúscula corresponde a substrato não diferem entre si, pelo teste de Tukey, a $1 \%$ de probabilidade, ${ }^{* \star}=$ significativo a $1 \%$ de probabilidade; SxC: Interação substrato e cultivar; ns=não significativo

Para diâmetro transversal pôde ser verificado interação significante entre SxC. Onde que a cultivar Rubi Gigante foi superior a cultivar Casca Dura Ikeda. Para substrato houve significância, onde $\quad 0$ substrato mistura $(C A+R S+P A+T P)$ apresentou resultado satisfatório, superior aos demais substratos (tabela 3), para as demais variáveis foram obtidos valores semelhantes, o que nos mostra que não houve variação entre um substrato e outro, obtendo êxito em cada um deles. 
A cultivar Rubi Gigante no substrato Caroço de açaí obteve menor diâmetro transversal $(0,07 \mathrm{~cm})$ apresentando não ser um bom substrato para a variável em análise (tabela 3). Resultados, contrários, aos obtidos por Borges (2005) o substrato com caroço de açaí carbonizada apresentou maior diâmetro de fruto de pimentão, devido ao caroço de açaí reter mais umidade e tornar a disponibilidade de nutrientes maior.

Em relação ao diâmetro Longitudinal houve efeito significativo na interação substrato e cultivar. Para cultivar, Casca Dura Ikeda apresentou melhor rendimento em relação a cultivar Rubi gigante. Os frutos no substrato de resíduo de soja obtiveram maior diâmetro, se mostrando ser um substrato promissor (Tabela 3).

Demais análises se apresentaram significativas em cada variável apresentada com exceção do caroço de açaí na cultivar rubi que obteve valor muito inferior as demais, tal fato pode ser justificado pelo caroço de açaí estar peneirado e pouco curtido, não retendo muita água. Resultado inferior ao de Erlacher (2014), onde a muda produzida em substrato à base de caroço de açaí triturado fermentado apresentou melhor resultado.

Para a característica de massa fresca, houve interação significativa para interação entre SXC, desta forma foi realizado o desdobramento entre os fatores, onde constatou-se que não houve efeito significante entre as cultivares. No entanto percebe-se efeito significativo nos substratos onde o substrato terra preta na cultivar Casca Dura Ikeda apresentou o melhor resultado para essa característica (Tabela 3).

Para massa total dos frutos de pimentão apresentou-se resposta significativa para a interação entre cultivar e substrato. Não havendo resposta significativa às cultivares. Para substrato a terra preta apresentou melhor resultado. Araújo et al. (2011) constataram maior eficiência da adubação orgânica no incremento da produção de biomassa e na absorção de nutrientes. Bissani et al. (2008) diz 
que os adubos orgânicos apresentam baixas concentrações de N, P e K, podendo ser complementados com adubação mineral, favorecendo o sincronismo de liberação ao longo do crescimento das plantas.

Verifica-se interação significativa entre os fatores cultivar e substrato (tabela 4) para as características de Área foliar específica (AFE), razão de peso foliar (RPF), índice área foliar (IAF) e peso específico da folha (PEF). Enquanto que para as características razão de área foliar (RAF) e quantidade de água na parte aérea (QAPA), observa-se um efeito significativo dentro de substrato para RAF e de cultivar para QAPA. Segundo Malavolta et al. (2002), os substratos não valem apenas pelos nutrientes que contêm, mas também por seus efeitos benéficos nos solos. A matéria orgânica funciona como fonte de energia para microrganismos úteis, melhora a estrutura e o arejamento a capacidade de armazenar umidade e tem efeito regulador na temperatura do solo.
Foi realizado uma análise de desdobramento para verificar qual fator apresentou melhores resultados para cada característica, não houve efeito significativo para a interação SxC e para substrato. Verificou-se efeito significativo para cultivar. Para RAF, Observa-se na tabela 4 que a cultivar Rubi gigante apresenta valores superiores a cultivar Casca Dura Ikeda. Para BENINCASA (2003), A RAF é um componente fisiológico, a razão entre - peso de matéria seca retida nas folhas e o peso de matéria seca acumulada na planta toda, sendo assim, expressa a fração de matéria seca não exportada das folhas para o resto da planta.

Para RPF, não houve efeito significativo na interação substrato e cultivar. Para cultivar houve efeito significativo, onde a cultivar Rubi Gigante foi superior em relação à cultivar Casca Dura Ikeda (Tabela 4). Para substrato não houve resultados significativos. Para SILVA et al. (2008) no pimentão foi verificado decréscimo na RPF, porém durante todo o ciclo. 
Para AFE não houve resultados significativo para interação entre SxC. Observou-se que a cultivar Rubi gigante foi superior a cultivar Casca dura Ikeda, apresentando valores significantes. Para substrato não houve resposta significativa. Para cultivar apresentou-se resultado satisfatórios onde a cultivar Rubi gigante obteve maior desempenho em relação a cultivar Casca Dura Ikeda. Para RADIN (2004) o declínio da AFE com o passar do tempo poderia ser devido ao acúmulo de material estrutural e também ao envelhecimento das folhas.

Para a característica PEF não houve efeito significativo sobre a interação cultivar e substrato (Tabela 4). Tendo efeito significativo para os substratos, onde o substrato palha de arroz na cultivar Casca Dura Ikeda apresentou melhor desempenho $\left(0,25 \mathrm{~g} \mathrm{dm}{ }^{2}\right)$. Houve enfeito significativo para cultivar, sendo que a cultivar Casca Dura Ikeda sobressaiu-se a cultivar Rubi gigante. (BORGES; GUERRERO; FERNANDES, 2010), em trabalhos com plantas de jambu, obtiveram média de
0,004 $\mathrm{g} \mathrm{cm}^{2}$ de PEF. Entretanto, no presente trabalho obteve-se média de $0,25 \mathrm{~g} \mathrm{~cm}^{2}$ de PEF para os pimentões, valor superior a referida autora.

Em relação à característica de QAPA, não houve efeito significativo entre a interação SxC e para substrato. Houve interação significativa para cultivar onde a cultivar rubi gigante foi superior a cultivar Casca Dura Ikeda, independente do substrato utilizado. (BORGES; GOTO; LIMA, 2014) em seu experimento com plantas de jambu cultivadas pela adubação orgânica e mineral, obtiveram médias de 216,33 g para a cultivar. Valores esses acima do encontrado neste trabalho que foram de 25,08 g no substrato terra preta na cultivar rubi gigante.

Para o índice de área foliar (IAF), houve efeito significativo entre a interação entre substrato e cultivar. $\bigcirc$ desdobramento entre eles foi realizado e contatou-se significância para as cultivares, onde a cultivar Casca Dura Ikeda foi superior a cultivar Rubi gigante. 
Tabela 4. Índices morfo-fisiológicos de crescimento, Razão de área foliar (RAF), razão de peso foliar (RPF), Área foliar especifica (AFE), peso específico da folha (PEF), quantidade de água na parte aérea (QAPA), índice área foliar (IAF), e em cultivares de Pimentão sob adubação de cinco diferentes substratos. Paragominas-Pa.

\begin{tabular}{|c|c|c|c|c|c|c|}
\hline SUBSTRATO & $\begin{array}{c}\text { RAF } \\
\left(\mathrm{dm}^{2} \mathrm{~g}^{-1}\right)\end{array}$ & $\begin{array}{c}\text { RPF } \\
\left(\mathrm{g} \mathrm{g}^{-1}\right)\end{array}$ & $\begin{array}{c}\text { AFE } \\
\left(\mathrm{dm}^{2} \mathrm{~g}^{-1}\right)\end{array}$ & $\begin{array}{c}\text { PEF } \\
\left(\mathrm{g} \mathrm{dm}^{2}{ }^{2}\right)\end{array}$ & $\begin{array}{c}\text { QAPA } \\
(\mathrm{g})\end{array}$ & $\begin{array}{c}\text { IAF } \\
\left(\mathrm{cm}^{2} / \text { planta }\right)\end{array}$ \\
\hline \multicolumn{7}{|c|}{$R \cup B I$} \\
\hline Caroço de Açaí & $33,88 \mathrm{bA}$ & $97,60 \mathrm{bA}$ & $39,80 \mathrm{bA}$ & $0,03 \mathrm{bB}$ & $24,41 \mathrm{aA}$ & $0,79 \mathrm{aB}$ \\
\hline Palha de arroz & $34,34 \mathrm{aA}$ & $98,01 \mathrm{aA}$ & $38,84 \mathrm{bA}$ & $0,05 \mathrm{aB}$ & $24,19 \mathrm{bA}$ & $0,79 a \mathrm{~B}$ \\
\hline Mistura $(P A+R S+C+T P)$ & $34,34 \mathrm{aA}$ & 98,01aA & $38,59 \mathrm{cA}$ & $0,04 a B$ & $24,16 \mathrm{bA}$ & $0,78 a \mathrm{~B}$ \\
\hline T. Preta & $34,88 \mathrm{aA}$ & $98,43 \mathrm{aA}$ & $38,63 \mathrm{bA}$ & $0,04 a B$ & $25,08 \mathrm{aA}$ & $0,77 \mathrm{bB}$ \\
\hline Resíduo de Soja & $33,88 \mathrm{bA}$ & $98,43 a A$ & $40,38 \mathrm{aA}$ & $0,05 \mathrm{aB}$ & $24,18 \mathrm{bA}$ & $0,76 b \mathrm{~b}$ \\
\hline \multicolumn{7}{|c|}{ IKEDA } \\
\hline Caroço de Açaí & $9,56 a \mathrm{aB}$ & $37,07 \mathrm{aB}$ & $16,06 \mathrm{abB}$ & $0,23 a A$ & $17,21 \mathrm{bB}$ & $1,10 c A$ \\
\hline Palha de arroz & $9,12 \mathrm{aB}$ & $35,97 \mathrm{bB}$ & $15,87 \mathrm{abB}$ & $0,25 a A$ & $18,11 \mathrm{aB}$ & $1,59 a A$ \\
\hline Mistura (PA+RS+C+TP) & $9,07 a B$ & $36,28 \mathrm{bB}$ & $17,32 \mathrm{aB}$ & $0,23 \mathrm{aA}$ & $17,99 \mathrm{bB}$ & $1,22 \mathrm{bcA}$ \\
\hline T. Preta & $8,86 \mathrm{bB}$ & $37,04 a B$ & 15,86abB & $0,24 \mathrm{aA}$ & $18,53 a \mathrm{~B}$ & $1,40 \mathrm{abA}$ \\
\hline Resíduo de Soja & $8,95 \mathrm{bB}$ & $36,40 a B$ & $14,45 b B$ & $0,23 a A$ & $18,24 a B$ & $1,49 a b A$ \\
\hline Substrato & NS & NS & ** & ** & NS & ** \\
\hline Cultivar & $\star *$ & $* *$ & 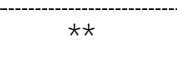 & $\star *$ & $* *$ & ** \\
\hline$S \times C$ & NS & NS & NS & NS & NS & $\star \star$ \\
\hline CV (\%) & 3,98 & 1,43 & 4,61 & 7,86 & 4,33 & 13,09 \\
\hline
\end{tabular}

Médias seguidas pela mesma letra maiúscula corresponde a cultivar não diferem entre si, médias seguidas pela mesma letra minúscula corresponde a substrato não diferem entre si, pelo teste de Tukey, a $1 \%$ de probabilidade, ${ }^{* *}=$ significativo a $1 \%$ de probabilidade; SxC: Interação substrato e cultivar; ns=não significativo.

Para substrato sobressaiu-se o substrato Palha de arroz com 1.59 $\mathrm{cm}^{2} /$ planta de IAF. RADIN et al. (2004) em seu experimento com alface observou que o índice de área foliar é maior quando cultivados em ambiente protegido.
A cultivar Casca dura Ikeda apresentou resultados satisfatórios, referentes às características avaliadas nas condições climáticas do município de Paragominas. Em relação ao desempenho do substrato, a cultivar Casca Dura Ikeda apresentou melhor rendimento no substrato resíduo de soja. 


\section{REFERÊNCIAS}

ARAÚJO, E. R.; SILVA, T. O.; MENEZES. R. S. C.; FRAGA, V. S.; SAMPAIO, E. V. S. B. Biomassa e nutrição mineral de forrageiras cultivadas em solos do semiárido adubados com esterco. Revista Brasileira de Engenharia Agrícola e Ambiental, v.15, n.9, p.890895, 2011.

BENINCASA, M. M. P. Análise de crescimento de plantas ( $8^{a}$ Ações Básicas). Ed. 2. Rev.Ampl. Jaboticabal: FUNEP, 2003, 41p.

BISSANI, C. A.; GIANELLO, C.; CAMARGO, F. A. O.; TEDESCO, M. J. Fertilidade dos solos e manejo da adubação das culturas. Porto Alegre, RS: Gênesis, 2008. 344p.

BORGES, L. S., GUERRERO, A. C., FERNANDES, D. M. Adubação foliar com silício no crescimento de plantas de jambu. Cultivando o Saber, Cascavel, v. 3, n. 1, p. 160-170, 2010.

BORGES, L. S.; GOTO, R.; LIMA, G.P. P. Índices morfo-fisiológicos e produtividade de cultivares de jambu influenciadas pela adubação orgânica e mineral. 6. ed. Uberlândia: Bioscience Journal, 2014. 1775 p. v. 30. Disponível em:<http://www.seer.ufu.br/index.php /biosciencejournal/article/view/22230> . Acesso em: 20 out. 2017.

BORGES, L. S.; GUERRERO, A. C.; GOTO, R.; LIMA, G. P. P. Exportação de nutrientes em plantas de jambu, sob diferentes adubações. Semina, Ciências
Agrárias, Londrina, v. 34, n. 1, p. 107116. 2013b.

BORGES, L. S.; VIANELLO, F.; MARQUES, M. O. M.; LIMA, G. P. P. Influence of Organic and Mineral Soil Fertilization and Essential Oil of Spilanthes oleracea. American Journal of Plant Physiology, v. 7, p. 135-142. 2012.

CALVETE, E. O.; SANTI, R. Produção de mudas de brócolis em diferentes substratos comerciais. Horticultura Brasileira, Brasília, v. 18, p. 483-484, jul. 2000. Suplemento.

CASAIS, L. K. N.; BORGES, L. S.; SOUSA, V. Q.; LIMA, M. Aproveitamento de resíduo de soja e palha de arroz como substrato para produção de mudas de jambu. Revista Brasileira de Agroecologia, Brasília, 2017

CASTRO, P. R. C.; FERREIRA, S. O.; YAMADA, T. Ecofisiologia da produção agrícola. Piracicaba: Associação Brasileira para Pesquisa da Potassa e do Fosfato, 1987. 249 p.

CHARLES-EDWARDS, D. A.; DOLEY, D.; RIMMINGTON, G. M. Modelling plant growth and development. North Ryde: Academic Press, 1986. 235 p.

CHARLO HCO; CASTOLDI R; FERNANDES C; VARGAS PF; BRAZ LT. 2009. Cultivo de híbridos de pimentão amarelo em fibra da casca de coco. Horticultura Brasileira, v. 27, p. 155-159, maio 2009. 
COSTA, E.; JORGE, M. H. A.; SCHWERZ, F.; CORTELASSI, J. A. S. Emergência e fitomassa de mudas de pimentão em diferentes substratos. Revista Brasileira de Ciências Agrárias, v. 8, n. 3, p. 396401, 2013.

EMBRAPA, Centro Nacional de Pesquisa de Solos, Rio de Janeiro. Sistema Brasileiro de Classificação de Solos, Brasília-DF: Embrapa Solos, 2008, 412p.

FALQUETO, A. R.; CASSOL, D.; MAGALHÃES JUNIOR, A. M.; OLIVEIRA, A. C.; BACARIN, M. A. Crescimento e partição de assimilados em cultivares de arroz diferindo no potencial de produtividade de grãos. Bragantia, v. 68, p. 563-571. 2009.

ERLACHER, W. A.; OLIVEIRA, F. L. de; SILVA, D. M. N. da; QUARESMA, M. A. L.; CHRISTO, B. F. Produção de mudas de hortaliças de fruto a partir de substratos formulados com caroço de açaí. Cadernos de Agroecologia, [S.I.], v. 8, n. 2, fev. 2014. ISSN 2236-7934. Disponível em: <http://abaagroecologia.org.br/revistas/index.php /cad/article/view/14345>. Acesso em: 31 ago. 2017.

FAULIN, E. J.; AZEVEDO, P. F. Distribuição de hortaliças na agricultura familiar: uma análise das transações. Informações Econômicas, v.33, n.11, p. 24-37, 2003.

FILGUEIRA, F. A. R. Manual de olericultura: Agrotecnologia moderna na produção e comercialização de hortaliças. Viçosa: UFV, 2000. 402p
FINGER, F. L.; SILVA, D. J. H. Cultura do pimentão e pimentas. In: FONTES, P. C. R. (ed.). Olericultura: teoria e prática. Viçosa: UFV, 2005. Cap. 27, p. 429- 437.

GALVÃO JCC; MIRANDA GV; SANTOS IC. Adubação orgânica. Revista Cultivar, v. 2, p. 38-41, 1999.

GUERRERO, A. C.; BORGES, L. S.; FERNANDES, D. M. Efeito da aplicação foliar de silício em rúcula cultivada em dois tipos de solos. Bioscience Journal, Uberlândia, v. 27, n. 4, p. 591-596. 2011.

MALAVOLTA, E.; PIMENTEL-GOMES. F.; ALCARDE, L. C. Adubos e adubações. São Paulo: Nobel, 2002. 200p.

MELO, S. C.; PEREIRA, H. S.; VITTI, G. C. Efeito de fertilizantes orgânicos na nutrição e produção do pimentão. Horticultura Brasileira, v. 18, p. 200-203, 2000.

MINISTÉRIO DO MEIO AMBIENTE. Gestão de Resíduos Orgânicos, 2017. Disponível em: <http://www.mma.gov.br/cidadessustentaveis/residuos-solidos/gestãode-resíduos-orgânicos>. Acesso em: 24 out. 2017.

PEREIRA, A. R.; MACHADO, E. C. Análise quantitativa do crescimento de comunidade vegetal. Campinas: Instituto Agronômico de Campinas, 1987. 33p. Boletim Técnico, 114

RADIN, B.; REISSER HNIOR, C.; MATZENAUER, R.; BERGAMASCHI, $\mathrm{H}$. Crescimento de cultivares de alface 
conduzidas em estufa e a campo. Horticultura Brasileira, Brasília, v. 22, n. 2, p.178-181, abril-junho, 2004.

RIBEIRO, G. L.; LOPES, J. C.; MARTINS FILHO, S.; RAMALHO, S. S. Adubação orgânica na produção do pimentão. Horticultura Brasileira, v. 18, p. 134-137, 2000.

RODRIGUES, E. T.; CASALI, V. W. D. Rendimento e concentração de nutrientes em alface, em função das adubações orgânica e mineral. Horticultura Brasileira, v. 17, p. 125-128, 1999.

ROE, N. E.; STOFFELLA, P. J.; GRAETZ, D. Composts from various municipal solid waste feedstocks affect vegetable crops. II. Growth, yields, and fruit quality. Journal American Society Horticultural Science, v. 122, p. 433437, 1997.

SEDIYAMA, M. A. N; GARCIA, N. C. P.; VIDIGAL, S. M.; MATOS, A. T. Nutrientes em compostos orgânicos de resíduos vegetais e dejetos de suínos. Scientia Agricola, v. 57, p. 185-189, 2000.

SILVA, P. I. B. Crescimento e partição de assimilados de pimentão em função de arranjos espaciais e espaçamentos na fileira. 2008. 58f. Dissertação (Mestrado em Agronomia) - Universidade Federal Rural do Semi-árido, Mossoró, RN, 2008

SOUZA, E. G. F.; BARROS JÚNIOR, A. P.; SILVEIRA, L. M.; SANTOS, M. G.; SILVA, E. F. Emergência e desenvolvimento de mudas de tomate IPA 6 em substratos, contendo esterco ovino. Revista Ceres, v. 60, n. 3, p. 902-907, 2013. 